\title{
Editorial
}

\section{Philosophy in Canada}

With this issue, we mark the twenty-fifth year of publication of Dialogue. To record this anniversary, we invited the two founding editors, Professor Venant Cauchy and Professor Martyn Estall, to record their observations on this occasion. We also issued a general invitation for the submission of articles and notes on the theme of "Philosophy in Canada". The theme was elaborated as follows:

Let me say something further about the theme "Philosophy in Canada". I take this to be a fairly broad designation to cover a variety of topics including the history of philosophy in Canada, the sense(s) in which there could or could not be a Canadian philosophy, philosophical reflection on Canadian problems (such as the Charter of Rights, Confederation, biculturalism and bilingualism), reflections on Canadian philosophical institutions (departments of philosophy, the CPA, Canadian philosophical journals, philosophical societies, and so on), discussion of significant Canadian philosophers and their works, future directions for philosophy in Canada (including relations to other academic disciplines). There may well be additional topics that you would like to recommend.

A number of anglophone philosophers responded to this invitation. After the submissions were duly refereed, the following were deemed publishable.

The invitation was a very broad one, and the response to it was quite varied. Other than issuing the general invitation and writing specific individuals who might be thought to have a special interest in this topic, no special attempt was made to provide a more unified result. It should be added here that the publication of these articles en bloc is not meant to foreclose further contributions on the topics suggested. Here, one area deserves special mention. This involves the preservation of what might well be labelled "institutional histories". While philosophy in Canada and in particular academic philosophy has a long history, it has expanded rapidly in recent years and undergone a number of important 


\section{Dialogue}

changes. Because most of us have been participants in this process, it is all too easy to assume that what is familiar and commonplace for us will be the same for our philosophical successors and heirs. Without suggesting any drastic changes in direction for this journal, it is worth remarking on the appropriateness of occasionally using some of these pages for reflection on such matters.

Finally and by far most importantly, it remains to thank all those who have made this journal possible over the past quarter of a century. Our thanks extends to those in the CPA who founded and sustained this journal over these years, to granting agencies-SSHRC and before that Canada Council who have assisted financially-to contributors and referees, and finally to our three predecessors-Venant Cauchy, Martyn Estall, and John Woods. We look forward to the next twenty-five volumes of Dialogue with hope and confidence.

MICHAEL MCDONALD Editor 